\title{
EFFECTS OF MOBILE APPLICATION TO THE PUBLIC TRANSPORTATION AND FUTURE EDITING: ISTANBUL CASE
}

\author{
İ. BEKTAŞ \\ Department of Transportation Planning, General Directorate of Istanbul Electricity Tunnel and Tramway, Turkey.
}

\begin{abstract}
It has been possible to see the effects of vertiginous enhancements in every sector by the side of technologic developments. Especially in communication sector, these developments have been seen in the form of paradigms. Wrapping of fibre optic network cables around the world quickly, increasing the number of communication satellites, and internet becoming a normal part of life have been made easier for people's communications. However, developments in communication tools have fostered to change not only human behaviours but also organization business processes. Organizations had begun to change their organizational structure very fast synchronously with these developments from approach of total quality, strategic planning to customer centric approach. Nowadays, thanks to smart mobile phones, organizations can get in touch with their customers more easily than ever, they can understand customer's needs, even needs that have not emerged yet, and in the direction of these needs they carry out $R \& D$ processes and new product development processes. Technologic developments in communication sector had changed not only customer centric business processes but also internal transactions of organizations, and also had ensured serious increase in productivity. In this paper, development of technologies has been evaluated and has been examined in the dimension of public transportation planning, and clues have been searched for question of how will be future by giving a place to IETTs' (Istanbul Electricity, Tunnel and Tramway, Istanbul Public Transportation Authority) studies in these fields.
\end{abstract}

Keywords: analytics, IETT, public transportation planning, smart application, smart phone, web.

\section{INTRODUCTION}

The rapid development and use of communication technologies and, at the same rate, involvement between people, easy accessibility to these instruments, especially vertiginous enhancements in web application, have fostered big change in the dimension of organization business processes in the past three decades. Not only integrated innovative leaps in web and communication technologies have generated new products such as smart mobile phones, social media platforms that people get connected easily, but also these improvements have generated big data that bring complexity for analysing these huge amount of data and converting them into information.

The evolution of production-oriented organizations is reserved briefly in three periods. First one was the production-oriented period before 1970s. Demand was high but due to lack of producers supply was low. Customers had to buy what producers offer them. Second one was quality productoriented period between 1970 and 1990. In that period, the number of producers has been increased and the effect of customers has also increased. Organizations had to produce more quality products to ensure loyalty of customers. Third one was customer-oriented period after 1990s. It was not enough to produce quality product for customers. Customers have the power of choosing any product in a large scale of product supply. Even power of making organization to produce customize product as customer wish. Last period has forced organizations not only to understand customer needs but also seek the way to reach customers. Transparent approach for customization (Yüksel, B. 1990) is an approach which envisages understanding the client without asking again and again, but still examining the needs of the client to interact and produce appropriate solutions to customers. However, for this approach to determine the client's needs in the 1990s was very difficult because of more limited data generated than the present. With the rapid development in Information and 
Communication Technology (ICT), many interactions, especially people's shopping habits, methods of communication began to change. Public and private organizations are increasing their investment in ICT. ICT has become the main element of public or private status of all business activities [1].

In this paper, information and communication developments in the field of web and smart phone technology and how to use it and work with these developments for public transportation planning and future vision for the IETT studies will be explained.

\section{CUSTOMER BEHAVIOUR}

The theories, both Justified Action Theory and the Theory of Planned Behaviour [2-4], have been developed and widely accepted among researchers to explain the behaviour in perspective of social psychology. In psychology, the theory of planned behaviour (abbreviated as TPB) is a theory, which links beliefs and behaviour. It has been applied to studies of the relations among beliefs, attitudes, behavioural intentions, and behaviours in various fields such as advertising, public relations, advertising campaigns, and health care. With this perspective, organizations realized marketing activities switching to customers centralized approach, understanding the customer, listening to even planning production processes with customers to produce and working on customer satisfaction for performing the highest level with the help of ICT.

Development of ICTs has facilitated the ease of gathering customer data. With the help of such systems on the internet as online customer tracking (OCT), organizations are able to make sense of these client data on an individual basis by following the customer communication with any online device and present suitable offers for customers with this evaluated information (Fig. 1).

\section{DEVELOPMENT OF WEB VERSION}

Between 1989 and 1999 years, with Web 1.0 people cannot just unilaterally make no interaction. It was an environment where the user is in a passive state by searching on the internet. During the years 1999-2009, people started interacting. People can share their thoughts on the site and have developed their own sites and blogs with Web 2.0. These activities have led to the increasing emergence of social media, which is quite common nowadays.

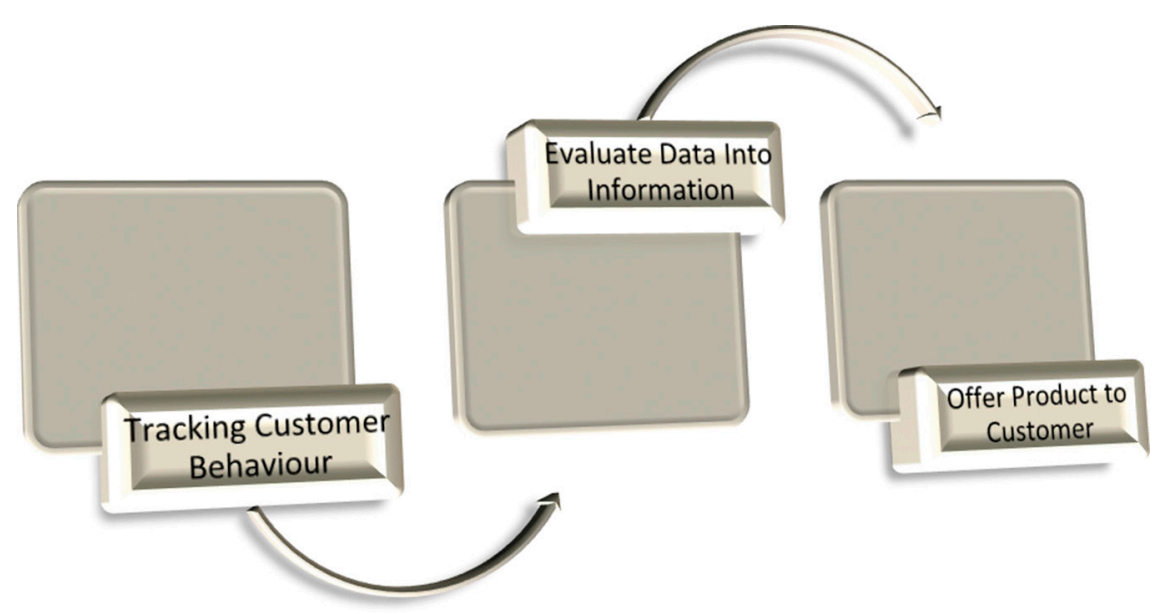

Figure 1: Marketing strategy based on customer tracking. 
Social online platforms, in any focused topic, have endorsed saying 'All the people, when they combined, they know more than a few people who specialize in that area regarding any issues' [5].

When surfing on the internet with this interaction, people have to leave their own distinctive digital footprints. This digital track, relevant with the people themselves, almost include some of the details such as time and logical attitude to their emotional state, including venue information, entertainment understanding to the political approach and a lot more constructs as 'Individuals Digital Information Map'.

\section{DEVELOPMENT OF SMART PHONE TECHNOLOGY}

Smart phone, a product of the world's PDA (personal digital assistant), is an advanced mobile communication, the features of the device being designed as a pocket computer with the addition of classic features provided by the mobile phone. Smart phones are equipped with mobile operating systems. In this manner, they can be used in a more active way for many different purposes and applications can be found for almost every need.

This situation has resulted in the formation of an information and communication platform that is more sophisticated and generate more data and individuals with the rapid increase in mobile phones development and the dizzying advances in smartphone penetration and usage. Smart phone usage rates in the world are shown in Table 1 [6].

Our Mobile Planet Turkey has conducted a survey with 1,000 private smartphone users, who use the internet in general, participated in the study. The survey indicates the context of the place of smartphones use for entire 2013 [7]. As can be seen in the graph, the user uses the smart phone in any environment. There is an increased smartphone usage rates in locations where user's mobility duration is stable. In Fig. 2, the context of the place of smartphones use is summarized.

Table 1: World smart phone number of connections per 100 citizens.

\begin{tabular}{lcr}
\hline Country rank & Connections/100 citizens & Population \\
\hline 1. Hong Kong & 236.8 & $7,219,700$ \\
2. Panama & 202.5 & $3,405,813$ \\
3. Saudi Arabia & 169.5 & $27,137,000$ \\
4. Lithuanian & 167.1 & $2,955,986$ \\
5. Estonia & 159.9 & $1,294,486$ \\
6. Russia & 155.5 & $142,905,200$ \\
7. Singapore & 151.8 & $5,312,400$ \\
8. Italy & 147.4 & $60,090,400$ \\
9. Malaysia & 143.8 & $28,250,000$ \\
10. Argentina & 141.34 & $40,134,425$ \\
11. Bulgaria & 140.2 & $7,600,000$ \\
12. United Arab Emirates & 139.6 & $8,264,070$ \\
13. Brasil & 136.45 & $201,032,714$ \\
14. Australia & 133 & $22,700,000$ \\
15. Germany & 130.1 & $81,882,342$ \\
50. Turkey & $\mathbf{8 9 . 9}$ & $\mathbf{7 5 , 6 2 7 , 3 8 4}$ \\
\hline
\end{tabular}




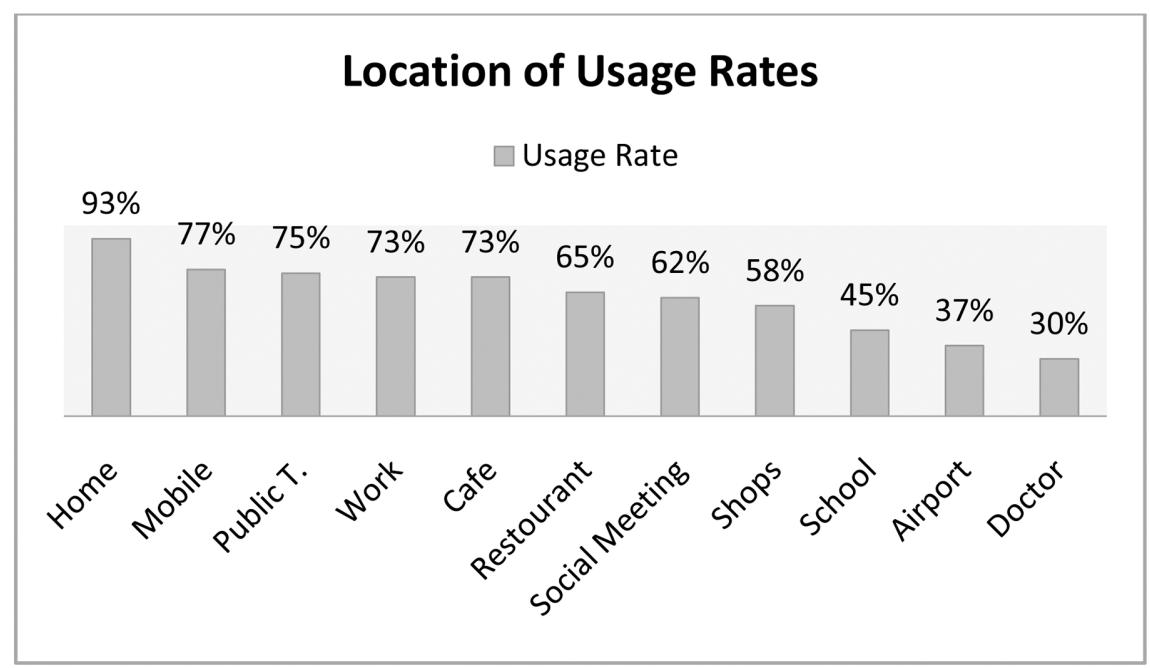

Figure 2: Location of usage rates.

\section{PUBLIC TRANSPORTATION PERSPECTIVE}

Every year seven cities are added, equivalent to New York, in the world. Becoming the cities as the centre of attraction has increased the gravity force from country to cities and has led to overcrowding of the urban population. Today, serious transportation problems have manifested in the big cities because of increasing urban population. The transportation problems delay or make an unattainable goal of the cities and the countries sustainable economic development.

These dizzying advances in Information and Communication Technologies have contributed to public transportation, which is a chronic problem with increasing urban population and private car ownership. The most innovative example is the electronic cards that are used for public transportation payment systems by many cities and countries in the world. Electronic cards have reduced the loss of revenue as well as passenger waiting time. Also, it provided making the public transport operators planning models and analysis more quickly with the passenger boarding data.

In Fig. 2, the statistical research that indicates that $75 \%$ of the users use smart phones during public transport should be underlined. Ensuring users to conduct the relocation process except their own mechanical activity reveals an interesting situation. Public transport users use smart phones for a variety of social media, game or entertainment applications when they are on the move in public transportation vehicles. This situation has led to the orientation of the public transport authorities to mobile applications. Mobiett is one of the most potent examples of these applications [8].

All public transport authorities use data that obtained from past electronic cards data for the assessment of basic planning principles, to make operational tactical and strategic plans in the world.

With rapidly increasing use of smart phones, internet users have left digital trail in the virtual environments that are began to be matched with real spatial points. Mobility of people has become well monitored together with the use of social media and Geographic Information System (Foursquare, etc.). Mobility in these researches is emerging to be specific to each person. This technological integration with public transport is seen as closely related with the following three perspectives [9]:

1. Map, place and route location.

2. Navigation, mobility and relocation.

3. Behaviour, reason of mobility and mode of mobility. 
In public transportation planning, the first two perspectives are the often used perspectives of planning. But the third perspective is not used. Instead of that, past trends are used for public transportation planning (Fig. 3).

IETT has started 'Public Transportation Navigation Project'. It is based on a system that integrates smartcard data and mobile application on a website-based platform. In Istanbul, population is over 14 million and the numbers of smartcards in use are over 16 million, and this number is increasing very fast as shown in Fig. 4. The number of usage is over 6 million on daily basis.

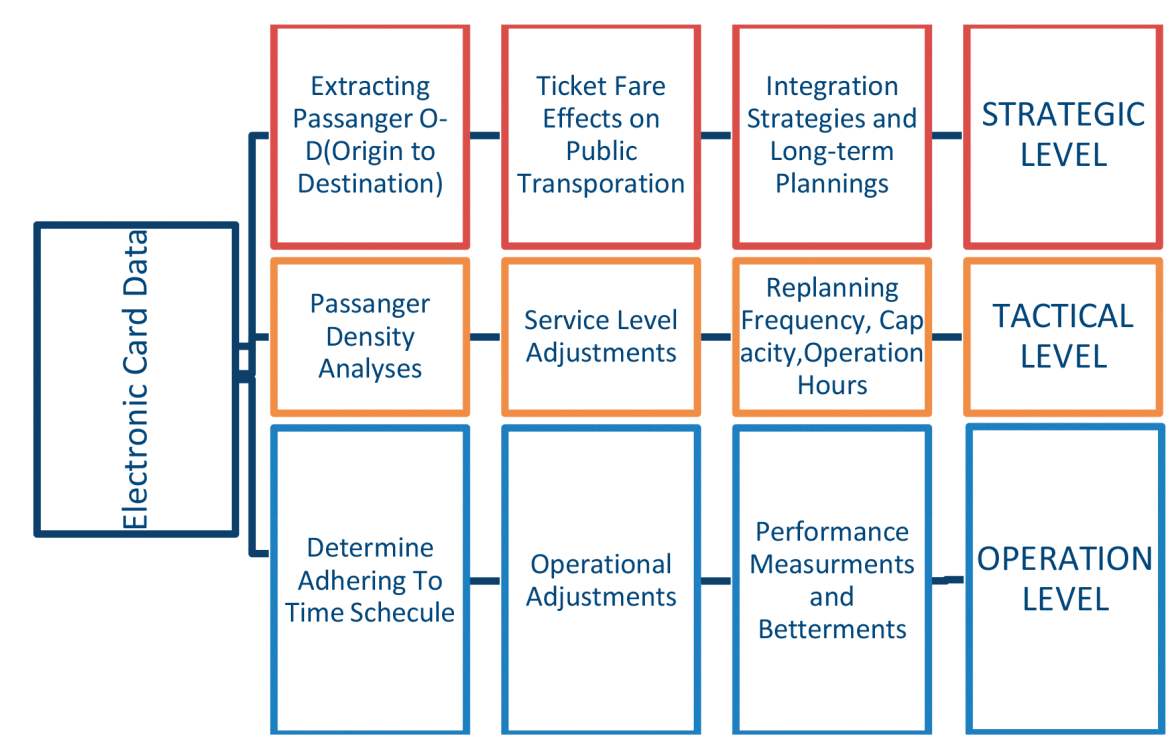

Figure 3: Three-level planning made with electronic card trip data.

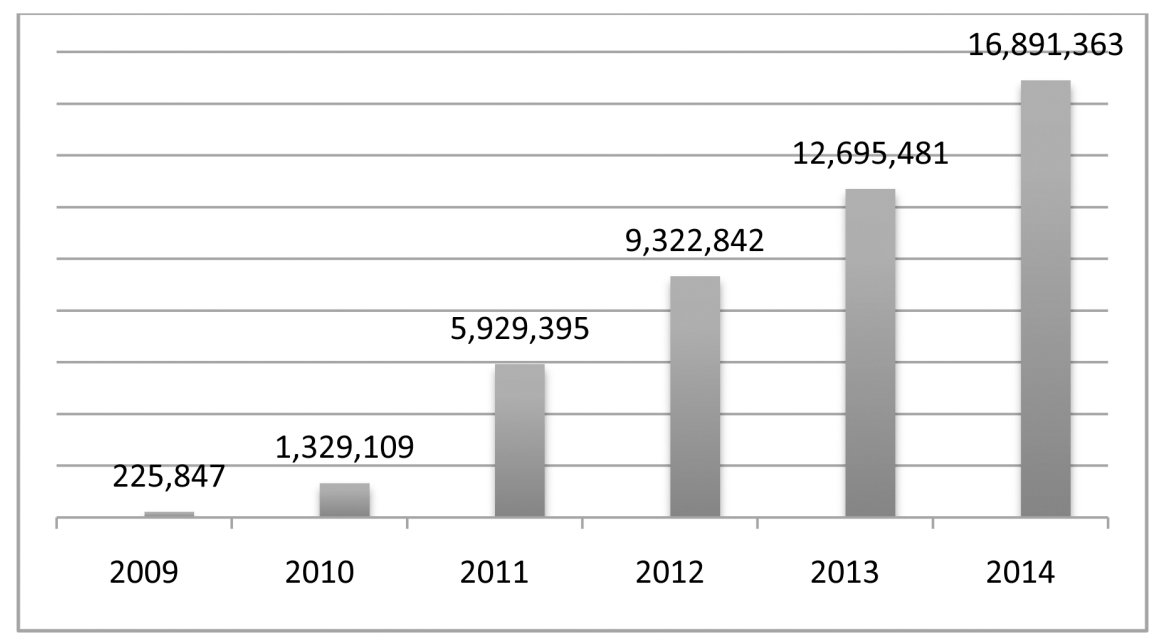

Figure 4: Numbers of Istanbulcards (Smardcard) in use by years. 
Table 2: Sample for number of passenger from origin to destination on the basis of bus stops.

\begin{tabular}{llccc}
\hline \multicolumn{5}{c}{ Alighting } \\
\hline Code of bus stops & A0284 & A1158 & A0285 & A0286 \\
\hline A0340 & 0 & 2 & 0 & 0 \\
A0339 & 1 & 1 & 1 & 0 \\
A0338 & 2 & 0 & 0 & 0 \\
A0337 & 1 & 0 & 0 & 0 \\
A0336 & 0 & 0 & 0 & 1 \\
A0334 & 0 & 0 & 0 & 0 \\
A0333 & 0 & 0 & 0 & 0 \\
A0332 & 0 & 1 & 1 & 0 \\
A1911 & 1 & 2 & 4 & 1 \\
A0754 & 0 & 0 & 0 & 0 \\
A3301 & 1 & 0 & 0 & 0 \\
A3302 & 0 & 0 & 1 & 0 \\
A3303 & 0 & 0 & 0 & 0 \\
\hline
\end{tabular}

Istanbulcard data are used for ridership analyses on public transportation infrastructure by IETT. It is possible to track every Istanbul card ID on the route. Tap-on is easy to track, for tap-off actions some analyses have to be made, but not so that difficult, and a sample calculated boarding and alighting is shown in Table 2.

IETT measures reliability punctuality performance with AVL (automatic vehicle location) system that enables to track vehicle in real time.

IETT aims to construct an online platform, which will gather and merge all types of data that it have. All Istanbulcard holders will be able to register this platform by smartcard ID. They will able to form their profile and will be provided all kinds of Istanbulcard transactions such as online payment and ordering new personalized Isatnbulcard, which are now available by Istanbulcard centres and prepayment machines. Platform is not limited for these kinds of functions. Platform will be supported by mobile application and Istanbulcard data. With data fusion of two big data, Istanbulcard data and AVL data, users will be able to see not only their journeys history on a simulation which will be formed with real personalized mobility data, but also real-time vehicle locations on the route, and they will be able to share that simulation on social media platforms. Their journey history will be recorded for scoring trips activity like scores according to transportation mode and contribution to sustainable transportation improvements.

Interaction with other registered users on platform will also take part in this project. With that users will be able to share public transportation information on communities that will be open for all users according to specifications such as users on the same route or mode, very fast.

There will be two modules apart from these common functions:

- Public transportation coaching (PTC) [10].

- Gamification. 


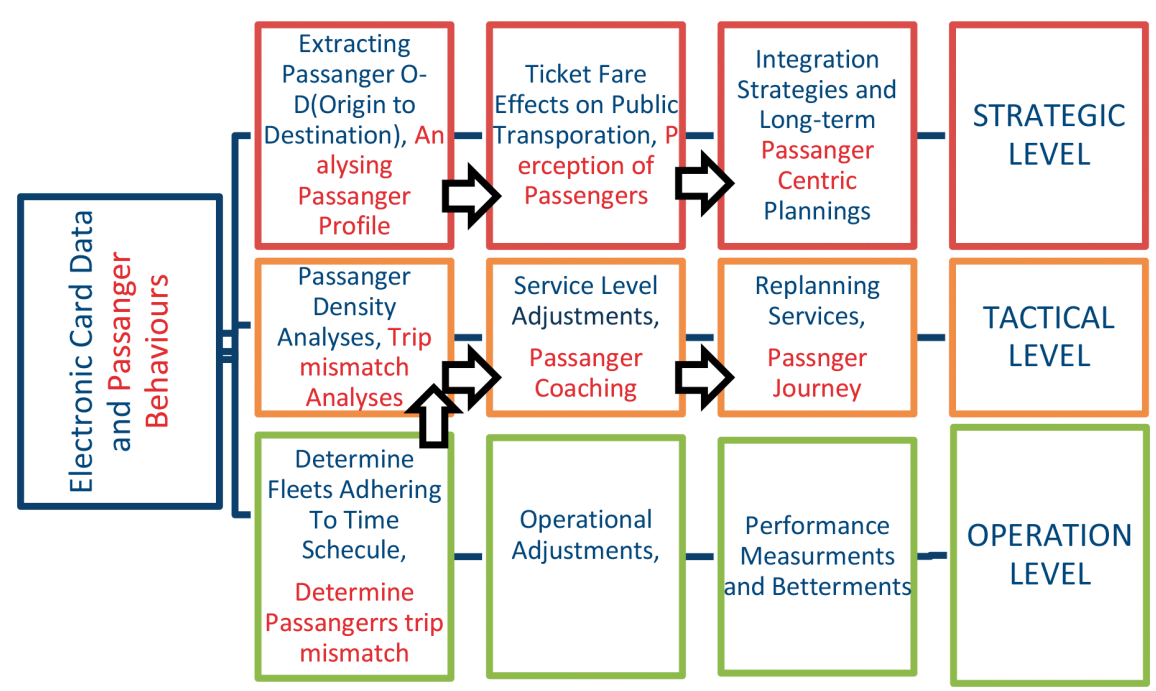

Figure 5: Three-level planning made with electronic card trip data and passenger behaviour.

PTC module will be activated as per demand of users. If a user want to join this module, the user will give permission to IETT track him/her by mobile application and personalized Istanbulcard data on public transportation infrastructures. After analysing user's journey experience, the module will offer to user an optimum new journey plan according to constrains (comfort, travel time, cost, etc.) that are determined by the user (Fig. 5).

Gamification module will be activated as per demand of users. Users will be scored on specific success missions. According to scores, users will gain ranks.

These modules will provide a unique opportunity for IETT to get in touch with its customer and understand their transportation needs, behaviours and take their contribution for planning. For example, if IETT prepare to invest on a new route one point to another, IETT will easily take passengers who use public transportation between this points, thoughts and collect demand to decide if the investment will be feasible or not in the terms of passenger's perception. That will prevent false investments or will improve sharpness of forecasts and increase customer satisfaction.

\section{CONCLUSION AND RECOMMENDATION}

Operational sense, public transportation couching service will direct passengers to compatible modes of public transportation.

Tactical sense: attraction centres will emerge with passenger data to be obtained easily.

Strategic sense: ticket prices can be removed from the fixed price to flexible pricing system with dynamic pricing for each individual passenger needs.

Results of 'Public Transportation Navigation Project' will be shared in the future paper.

\section{REFERENCES}

[1] Hu, P.J., Chau, P.Y., Hu Sheng, O.R. \& Tam, K.Y., Examining the technology acceptance model using physician acceptance of telemedicine technology. Journal of Management Information Systems, 16(2), pp. 91-112, 1999. 
[2] Ajzen, I., From intentions to actions: a theory of planned behavior. Action Control, From Cognition to Behaviour, eds. J. Kuhl \& J. Beckman, Springer-Verlag: Berlin, Heidelberg, pp. 11-39. 1985.

[3] Ajzen, I., The theory of planned behaviour. Organization Behaviour and Human Decision Process, 50, pp. 179-211, 1991. http://dx.doi.org/10.13072/midss.649

[4] Fishbein, M. \& Ajzen, I., Belief, Attitude, Intention and Behavior: An Introduction to Theory and Research, Addison-Wesley: Reading, MA, 1975.

[5] Nash, A., Web 2.0 applications for improving public participation in transport planning, Transportation Research Board 89th Annual Meeting Vienna Transport Strategies, Austria, 2009.

[6] List of countries by number of mobile phones in use. http://en.wikipedia.org/wiki/List_of_ countries_by_number_of_mobile_phones_in_use (accessed 28 April 2015).

[7] Our Mobile Planet, Understanding Mobile Consumer Turkey Report. http://services.google. com/fh/files/misc/omp-2013-tr-local.pdf (accessed 28 April 2015).

[8] http://www.iett.gov.tr/tr/main/news/mobiett-ile-artik-her-durak-akilli/1397

[9] Goodchild, M.F., GIS and transportation: status and challenges. J Geoinform, 4(2), pp. 127-139, 2000.

[10] Bektas, I., Mobil Uygulamalardaki Gelisimin Toplu Ulaşima Etkisi ve Gelecek Kurgusu. TRANSIST 2014 Papers, pp. 252-259, 2014. 